\title{
A STUDY ON THE THREE-PHASE SEPARATOR MACHINE (TRICANTER) FOR OLIVE OIL EXTRACTION
}

\author{
ASHKAN SHOKRIAN ${ }^{1}$, HOSSEIN MOBli $^{2 *}$, ABbas AKBARnia ${ }^{3}$, \\ ALI JAFARI $^{2}$, HOSSEIN MOUSAZADE ${ }^{2}$, BAOSHAN ZHU ${ }^{4}$ \\ ${ }^{1}$ College of Agriculture \& Natural Resources, University of Tehran, \\ Karaj, Iran \\ ${ }^{2}$ College of Agriculture \& Natural Resources, University of Tehran, \\ Tehran, Iran \\ ${ }^{3}$ Iranian Research Organization for Science and Technology, Karaj, Iran \\ ${ }^{4}$ Department of Energy and Power Engineering, Tsinghua University, \\ Beijing, China
}

[Received: 26 November 2018. Accepted: 13 May 2019]

doi: 10.7546/JTAM.49.19.03.03

\begin{abstract}
The present study is a simulation by using Computational Fluid Dynamics (CFD) technique for the multiphase complex fluid flow motion in a centrifugal separate machine (tricanter). The CFD model uses Volume of Fluid multiphase model coupled with Reynolds Stress turbulence model for two-phase flow predictions. This centrifugal device is designed for separated three-phase flow, two- phase liquid (water and olive oil) and one phase solid materials (olive pomace). The contours of pressure, velocity and volume fraction of each phase were obtained by CFD simulation. The results showed that the centrifuge machine is designed well to separate three different phases.
\end{abstract}

KEY WORDS: centrifugal separate machine (tricanter), computational fluid dynamics (CFD), three-phase, olive oil.

\section{INTRODUCTION}

A tricanter centrifuge is a device that uses centripetal acceleration to continuously separate a mixture of particulate solids and a liquid, where the solids have higher density than the liquid. The versatility of tricanter centrifuges has led to their widespread use in industrial applications [1]. Olive oil is the most widely used fat in the diet of Mediterranean countries, thanks especially to its healthy properties, unique aroma and long shelf life, and due to its natural antioxidant content, which make it different from other vegetable oils [2].

Evolution of the oil extraction process has led to the replacement of traditional discontinuous lines, using the pressure system extraction, with continuous ones, using

\footnotetext{
${ }^{*}$ Corresponding author e-mail: hmobli@ut.ac.ir
} 
centrifugal extraction. In particular, the horizontal centrifuge with a screw conveyor (i.e. tricanter) is widely used in olive oil extraction, especially if large amounts of olives have to be processed in a short time [3,4]. However, olive oil extraction by centrifuge is dramatically affected by changes in the rheological characteristics of the olive paste in relation to water content, fruit variety, maturity level and seasonal temperature variations [5].

ANSYS Fluent is used for simulation and prediction of fluid flow. ANSYS Fluent software contains the broad physical modeling capabilities needed to model flow, turbulence, heat transfer, and reactions for industrial applications [6].

\section{Materials And Methods}

Centrifugal horizontal machine (Tricanter) has become a major processing tool in a wide range of liquid/solid separation applications. Although a complicated piece of machinery, the tricanter centrifuge embodies a simple principle, that of the screw conveyor [7].

The tricanter centrifuge is, in principle, a relatively simple device, though far from simple to manufacture, being a rotating drum with a screw conveyor in it; clarified liquid decants out of one end while dewatered solids are scrolled out of the other. The prime virtue of the tricanter is its ability to remove quite high levels of suspended solids from a liquid, with a reasonably low level of retained liquids in the separated solids.

A schematic of a tricanter centrifuge is shown in Fig. 1, with an example of dimensions and operating parameters for a typical application listed in Table 1.

Table 1. Example parameters for a tricanter centrifuge separating

\begin{tabular}{lc}
\hline \hline Variable & Value \\
\hline Liquid density & $800 \mathrm{~kg} / \mathrm{m}^{3}$ \\
Solid density & $2010 \mathrm{~kg} / \mathrm{m}^{3}$ \\
Rotation speed & $3000 \mathrm{RPM}$ \\
Differential speed & $40 \mathrm{RPM}$ \\
Mass flow rate & $0.25 \mathrm{~kg} / \mathrm{s}$ \\
Liquid discharge radius & $20 \mathrm{~mm}$ \\
Solid discharge radius & $20 \mathrm{~cm}$ \\
Scroll pitch & $50 \mathrm{~mm}$ \\
Scroll pitch angle & $12^{\circ}$ \\
Bowl radius & $160 \mathrm{~cm}$ \\
Cone half angle & $12^{\circ}$ \\
Length of conical section & $300 \mathrm{~mm}$ \\
Length of cylindrical section & $400 \mathrm{~mm}$ \\
\hline
\end{tabular}




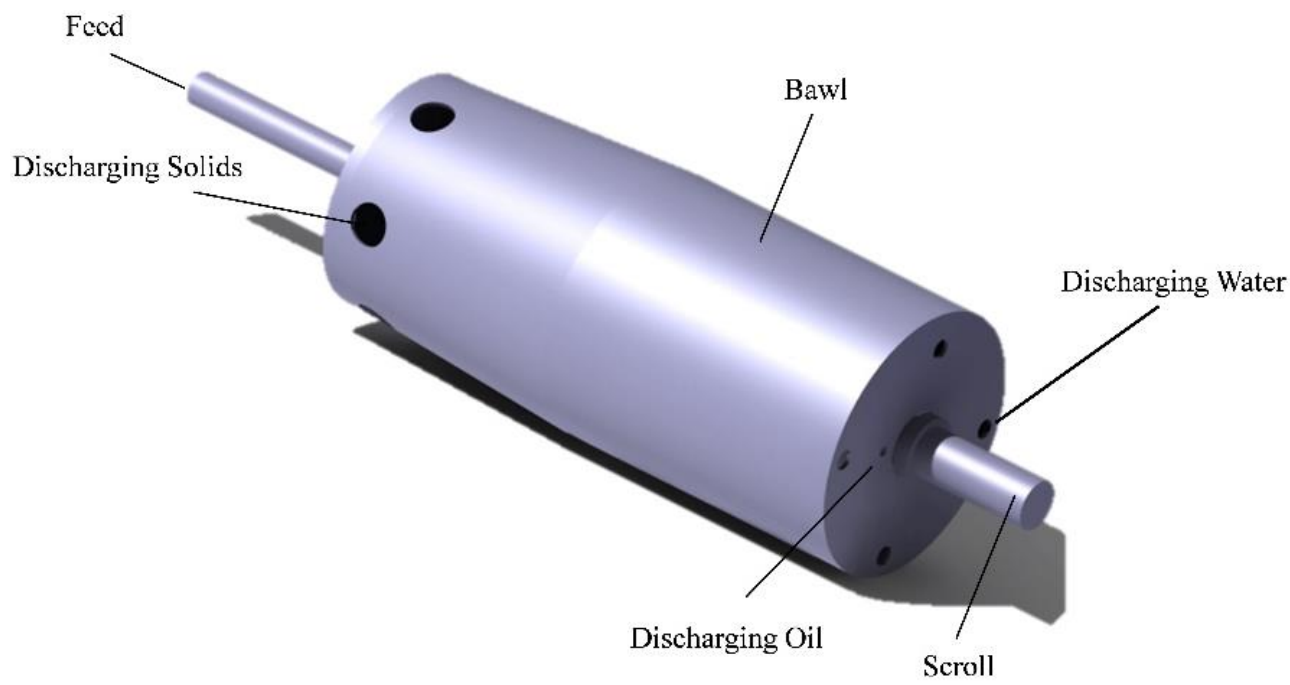

Fig. 1. (Color online) Schematic of a tricanter centrifuge.

\section{$2.1 \quad$ BASIC THEORY}

In the centrifuge, it is the liquid that moves round in a circle, and the particles in suspension are free to move relative to the liquid. Thus, relative to the liquid, the suspended particles experience an acceleration, $\omega^{2} r$, radially outwards.

Thus, the gravitational force, $F$, on a particle of mass $m$, is the product of its mass and acceleration, where

$$
F=m r \omega^{2} .
$$

In centrifuge parlance the term " $g$ " (or $g$-level) is often used. This is the number of times the acceleration in the centrifuge is greater than that due to gravity alone [7].

\subsection{Methodology}

Flow governing equations in terms of Navier-Stokes equations are solved. Multiphase simulation flow inside the tricanter machine is resolved by VOF method. We used ANSYS CFX software package for simulation of fluid motion in the centrifugal tricanter. The CFD simulation allows us to predict the performance of a tricanter machine [8].

\subsection{VOF MODEL}

VOF model is a numerical technique used for tracking the interface between free surfaces by solving the momentum (2). Continuity (3) is solved for the volume fraction 
of the air $\left(\alpha_{q}\right)$ and this tracks the position of the air core in this problem [9].

$$
\begin{gathered}
\frac{\partial\left(\rho u_{j}\right)}{\partial t}+\frac{\partial\left(\rho u_{i} u_{j}\right)}{\partial x_{i}}=-\frac{\partial p}{\partial x_{i}} \rho g_{i}+\frac{\partial}{\partial x_{i}} \mu\left(\frac{\partial u_{i}}{\partial x_{j}}+\frac{\partial u_{j}}{\partial x_{i}}\right), \\
\frac{\partial \alpha_{q}}{\partial t}+u_{j} \frac{\partial \alpha_{q}}{\partial x_{i}}=0,
\end{gathered}
$$

where $\alpha_{q}$ is the volume fraction of the $q$-th phase, which varies between 1 and 0 . $u_{j}$ is the $j$-th component of the velocity. A constant value of $0.078 \mathrm{~N} / \mathrm{m}$ is used for the surface tension between air and water. The average density and viscosity are calculated by the following manner [9]:

$$
\begin{aligned}
& \rho=\alpha \rho_{\text {water }}+(1-\alpha) \rho_{\text {air }}, \\
& \mu=\alpha \mu_{\text {water }}+(1-\alpha) \mu_{\text {air }} .
\end{aligned}
$$

\subsection{OLIVE SAMPLES}

This study included olive oil samples produced from olives (Fashemi) of the Manjil cultivar, which is considered as the most prized Iranian olive variety for oil production, originating from the area of Gilan province, Iran. This variety grows well on mountain slopes and produces small fruit; the high ratio of skin to flesh giving the oil its coveted aromatic qualities. Olive fruits grown in an organic farm in Manjil, were picked by hand during February 2014. The maturity of olive fruits was confirmed by their color: $70 \%$ were green and $30 \%$ brown. Olives' average diameter was $12.8 \mathrm{~mm}$ and their average weight was $0.78 \mathrm{~g}$. Overall, $200 \mathrm{~kg}$ of olive fruits were collected.

\section{Results AND Discussion}

\subsection{SOLID VELOCITY}

The contour velocity profiles of solid materials inside tricanter machine are displayed in Fig. 2. It can be seen that the velocity of solid material in near to the surface shell has maximum value, but the velocity near the outer scroll is zero, and causes the suspended solids to settle and accumulate at the scroll wall.

Increasing the differential speed between bowl and scroll from $40 \mathrm{rpm}$ to $120 \mathrm{rpm}$ provides the conveying motion to collect and remove the solids, which accumulate at the scroll wall (Fig. 3).

\subsection{PRESSURE}

The highest pressure occurs at the entrance of the separator, where the flow velocity is also decreased. It was noticed that the pressure at the middle of the tricanter was lower than atmospheric pressure and ideally lower than the inflow inlet for the tricanter to have optimum efficiency (Fig. 4). 


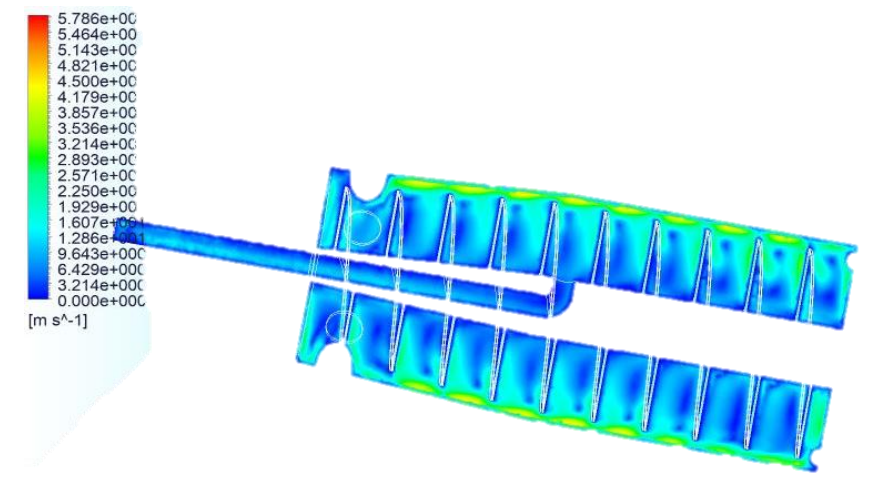

Fig. 2. (Color online) Solid materials velocity counter.

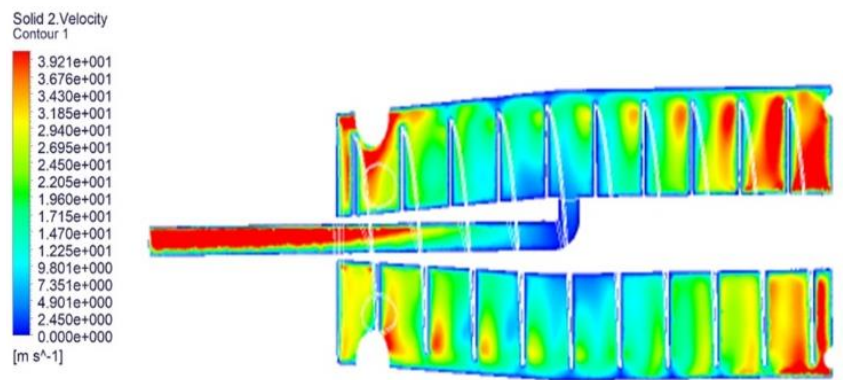

Fig. 3. (Color online) Solid materials velocity contour after the increase of the differential speed.

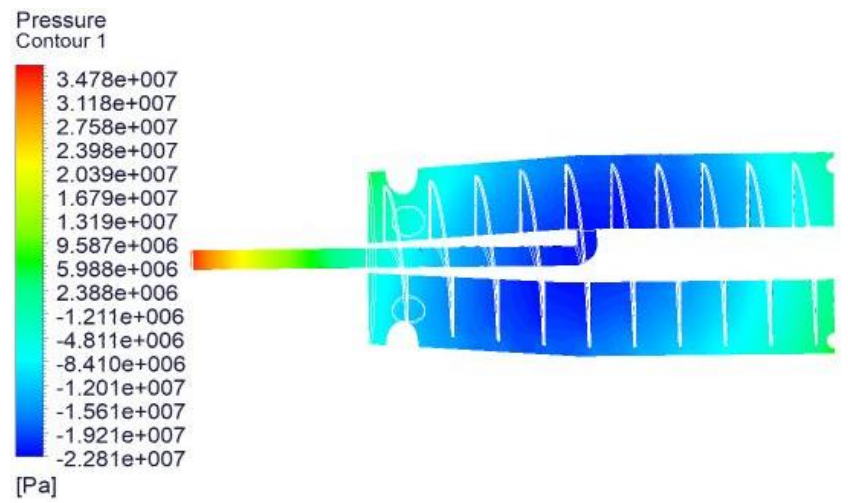

Fig. 4. (Color online) Pressure contour inside the tricanter machine. 


\subsection{VOLUME FRACTION}

According to Fig. 5a, biggest oil concentration is near to the scroll, and this is due to the lower density of the oil than the density of oil and solid materials. Also, the water concentration is close to the centrifugal rotor (scroll) body. According

(a)

Oil.Volume Fraction

$$
\text { Contour } 1
$$

9.697e-001

$9.091 \mathrm{e}-001$

$8.485 \mathrm{e}-001$

$7.879 \mathrm{e}-001$

$7.273 e-001$
$6.667 e-001$

6.061e-001

5.455e-001

$4.848 \mathrm{e}-001$

4.242e-001

3.636e-001

$3.030 \mathrm{e}-001$

$2.424 \mathrm{e}-001$

$1.818 \mathrm{e}-001$

1.212e-001

$6.061 \mathrm{e}-002$
$1.080 \mathrm{e}-007$

Fluid 1.Volume Fraction

Contour 1

\subsection{9e-001}

8.352e-001

7.795e-001

7.239e-001

6.682e-001

$6.125 \mathrm{e}-001$

$5.568 \mathrm{e}-001$

5.011e-001

$4.455 \mathrm{e}-001$
$3.898 \mathrm{e}-001$

3.341e-001

2.784e-001

2.227e-001

$1.670 \mathrm{e}-001$

$1.114 \mathrm{e}-001$

$5.568 \mathrm{e}-002$

$1.699 \mathrm{e}-010$

Solid 2.Volume Fraction

Contour 1

9.406e-002

$8.818 \mathrm{e}-002$

$8.230 \mathrm{e}-002$

$7.642 \mathrm{e}-002$

$7.054 \mathrm{e}-002$

6.467e-002

5.879e-002

(c)

$5.291 \mathrm{e}-002$

$4.703 \mathrm{e}-002$
$4.115 \mathrm{e}-002$

$4.115 \mathrm{e}-002$
$3.527 \mathrm{e}-002$

$2.939 \mathrm{e}-002$

2.351e-002

$1.764 \mathrm{e}-002$

$1.176 \mathrm{e}-002$

$5.879 \mathrm{e}-003$

$0.000 e+000$

Fig. 5. (Color online) Volume fraction contour: Oil (a), Water (b), Solid materials (c). 
to Figs. $5 \mathrm{~b}$ and $5 \mathrm{a}$, it can be proved that the lowest concentration occurs where the water concentration is bigger. This shows that the separation of the mixture starts around the centrifugal rotor.

Figure $5 \mathrm{c}$ shows that the suspended solid materials settle and accumulate at the shell wall because the density of the solids is higher than the density of water and oil.

\section{CONCLUSiON}

The overall results reported in this paper show that the centrifugation system strongly separate each phase. A slurry of liquid and suspended solids is fed along the center line to some fixed position within the bow, and is accelerated outwards to join the pond of liquid held on the bowl wall by the centrifugal force. This same force then causes the suspended solids to settle and accumulate at the bowl wall. In this paper the flow inside the tricanter is simulated by Computational Fluid Dynamics (CFD) technique. The CFD model uses Volume of Fluid multiphase model coupled with Reynolds Stress turbulence model for three-phase flow predictions.

Inside the tricanter centrifuge the separation of water, oil and solid parts are performed efficiently. At the outlet it is possible to see, that on the water outlet comes out water, on the oil outlet comes out oil and on the solid particles outlet come out solid particles, mainly.

\section{ACKNOWLEDGEMENTS}

The authors would like to thank the Iranian national science foundation (INSF) and Iranian Research Organization for Science and Technology for funding and supporting this project (Grant No.93006663) during 2015-2018.

\section{REFERENCES}

[1] G.R.A. Bell, D.B. Symons, J.R. Pearse (2014) Mathematical Model for Solids Transport Power in a Decanter Centrifuge. Chemical Engineering Science Pearse 107 114-122.

[2] M. Salvador, F. Aranda, S. Gomez-Alonso, G. Fregapane (2013) Influence of Extraction System, Production Year and Area on Cornicabra Virgin Olive Oil: A Study of Five Crop Seasons. Journal of Food Chemistry 80(3) 359-366.

[3] A. Ranalli, G. De Mattia, M.L. Ferrante (1997) Comparative Evaluation of the Olive Oil Given by a New Processing System. Journal of Food Science and Technology 32(4) 289-297.

[4] P. Piacquadio, D.S. Giovanni, V. Sciancalepore (1998) Quality of Virgin Olive Oil Extracted with the New Centrifugation System Using a Two-Phases Decanter. Fett/Lipid 100(10) 472-474. 
[5] G. Altieri (2010) Comparative Trials and an Empirical Model to Assess Throughput Indices in Olive Oil Extraction by Decanter Centrifuge. Journal of Food Engineering 97(1) 46-56.

[6] T.S. Kannan, S.A. Mutasher, Y.H. Kenny (2013) Design and Flow Velocity Simulation of Diffuser Augmented Wind Turbine Using CFD. Journal of Engineering Science Technology 8(4) 372-384.

[7] A. Records, K. Sutherland (2001) "Decanter Centrifuge Handbook". Elsevier Science.

[8] A. Davailles E. Climent, F. Bourgeois (2012) Fundamental Understanding of Swirling Flow Pattern in Hydro Cyclones. Separation Purification Technology 92 152160.

[9] C.W. HiRT, D.N. Billy (1981) Volume of Fluid (VoF) Method for the Dynamics of Free Boundaries. Journal of Computational Physics 39(1) 201-225. 